\title{
The material parameters for computational modeling of long-fibre composites with textile
}

\author{
Jan Krmela ${ }^{1, *}$, Vladimíra Krmelová ${ }^{1}$ \\ ${ }^{1}$ Alexander Dubček University of Trenčín, Faculty of Industrial Technologies, I. Krasku 491/30, 02001 \\ Púchov, Slovakia
}

\begin{abstract}
In this contribution, the composites with textile fibre (cord) and an elastomer matrix are studied based on computational modeling of car tires in combination with experiments. These composite are applied in tire casings for cars, conveyor belts etc. The aim of this research work of authors is creation of computational models namely for stress-strain analyses of selected parts of radial tire casing. The typically passenger car radial tire casing consists of one or two polyester plies in tire carcass and two steel-cord belts and one polyamide 66 cap ply below tread. The finite element method using the program system ANSYS is applied to the computational modeling. For the determination of the material parameters of elastomer and textile cords as input data to the computational models, it was necessary to perform tests as statically tensile tests. Also the experiments of composites as tests of low cyclic loading of composites are needed for verification analyses between computational results and experimental data. For computational modeling, the modulus of elasticity and Poisson ratio are used as material input parameters of textile reinforcements. The results from the computational modeling and selected results from the tests are presented in this contribution.
\end{abstract}

Keywords: tire, ANSYS, material parameters, tensile test, low cycle loading, PA66

\section{Introduction}

The paper deals with the long-fiber composites with textile fibre. A tire casing can be classified as a long-fiber composite with polymer matrixes - an elastomer and longfilament reinforcements - textile and steel cords.

It is necessary to have knowledge about geometry, material parameters, cross-section and structure of a tire casing (number of layers of a belt and carcass, information about a bead and cap ply) and other parameters for creations of computational models of a tire casing for the strain-stress analysis of a tire under the vertical load, modal analysis etc.

A standard automobile radial tire casing consists of elastomer parts and parts with textile-cords (Tab. 1) and steel-cords in a tire tread as reinforcements. The structure parts applied into passenger car radial tire casings are: textile carcass plies, a textile cap ply (called an overlap belt) and steel-cord belts $[1,2]$. These structures of a tire have a different cord material, cord angle (e.g. for a steel belt there is applied an angle of $21-27^{\circ}$ in a radial

\footnotetext{
* Corresponding author: jan2.krmela@post.cz

Reviewers: Jozef Bocko, Justín Murín
} 
tire casing for a passenger car), the construction of cord and number of layers (single-layer or multi-layer). Therefore, tires have specific deformation properties. The textile carcass density (it is a number of ends per one meter of width, marked as EPM) is from 700 to $1150 \mathrm{~m}^{-1}$. The EPM of a textile cap ply is $1100-1200 \mathrm{~m}^{-1}$. The PA66 and PES textile fibers are used for passenger tires, especially for common purposes.

Table 1. Materials of textile-cords for tires [2]

\begin{tabular}{|c|c|c|}
\hline Material & $\begin{array}{c}\text { Labeling of } \\
\text { construction [tex] }\end{array}$ & Application \\
\hline Polyester & $\begin{array}{l}\text { PES } 144 \times 1 \times 2 \\
\text { PES } 167 \times 1 \times 3\end{array}$ & Carcass plies \\
\hline Polyamide 6 & $\begin{array}{l}\text { PA6 94x1x2 } \\
\text { PA6 94x1 }\end{array}$ & Cap ply \\
\hline Polyamide 66 & PA66 140x1x2 & Cyp ply \\
\hline Rayon (viscose) & $\begin{array}{l}\text { VS } 184 \times 1 \times 2 \\
\text { VS } 244 \times 1 \times 2\end{array}$ & Carcass plies \\
\hline Aramid & Aramid 110x1x2 & $\begin{array}{l}\text { Carcass plies for sport } \\
\text { tire casings }\end{array}$ \\
\hline
\end{tabular}

The input data for computational modeling are divided to geometric and materials parametres obtained in an experimental way. For computational modeling the elastic modulus of elasticity and Poisson ratio are used as material input parameters of textile reinforcements. The static tensile modulus of elasticity of PA66 is from 900 to $3450 \mathrm{MPa}$ or from 9 to $50 \mathrm{cN} / \mathrm{dtex}[2,3]$. It is a broad range. In case of rayon, the modulus is from 600 $\mathrm{MPa}$ to $11 \mathrm{GPa}$ or $8-120 \mathrm{cN} / \mathrm{dtex}$. The Poisson ration of PA66 is approx. 0.4. Typically, values of modulus of elasticity are in Tab. 2. The samples of cross-sections of tire casings in the area of tire-crown are in Fig. 1 for the tire Dunlop 215/40 R17 87V (low-profile, extra load) for sport cars.

Table 2. Moduli of elasticity of textile cords [3]

\begin{tabular}{|c|c|}
\hline Material & $\begin{array}{c}\text { Modulus of elasticity } \\
\text { [GPa] }\end{array}$ \\
\hline Polyester & 4 \\
\hline Polyamide 66 & 3.4 \\
\hline Rayon (viscose) & 11 \\
\hline Aramid & 25 \\
\hline
\end{tabular}

The EPM of the textile cap ply of 215/40 R17 is approx. $1400 \mathrm{~m}^{-1}$. The diameter of cords is $0.44 \mathrm{~mm}$ and the thickness of the cap ply is approx. $1.1 \mathrm{~mm}$. The textile carcass has $0.5 \mathrm{~mm}$ diameter of cords and the thickness is approx. $1.5 \mathrm{~mm}$. The steel cord belts consist of two plies with a density of $650-680 \mathrm{~m}^{-1}$ and the cord construction is $2+2 \times 0.30 \mathrm{~mm}$. The thickness of the steel cord belt (two plies altogether) is $1.4 \mathrm{~mm}$. Further information about the structure is in the paper [4].

The geometric parameters, which were obtained by an image analysis of the crosssection, will be used as necessary geometric input data in order to create a computational model with a real configuration of cords. The results can be used for an optimization of the deposition angle of textile reinforcement in composites. 


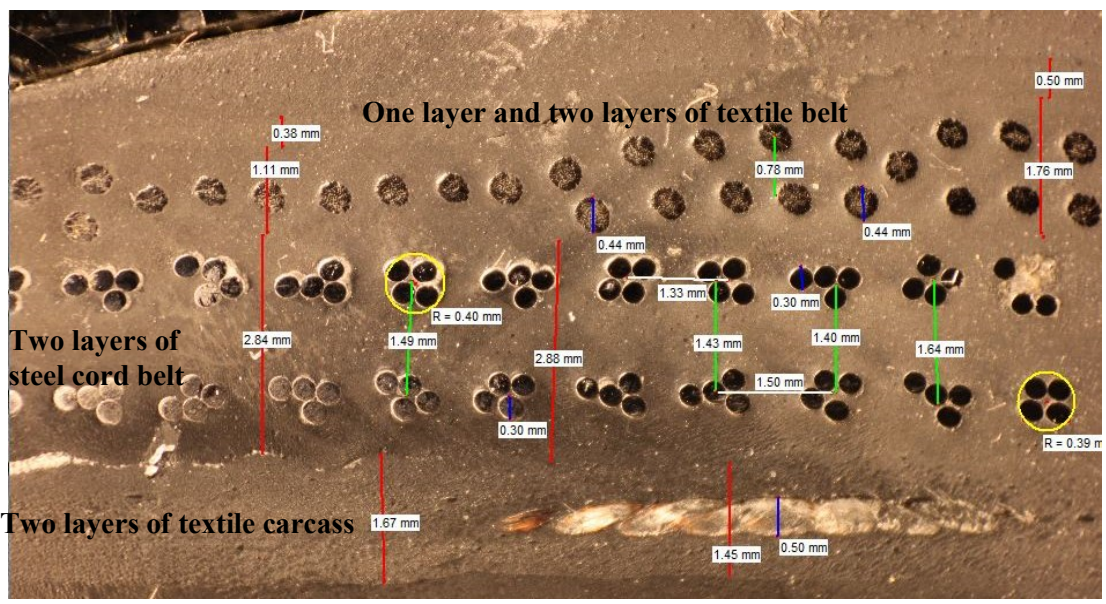

Fig. 1. The detail of structure of the tire-crown 215/40 R17

\section{Experimental part}

Tests of specific long-fiber composite materials with an elastomer are not standardized. The tire casing 215/40 R17 were cut with a water jet in the longitudinal and transverse direction in order to obtain the specimens for statical tensile tests The specimens were prepared with different width 15 and $20 \mathrm{~mm}$. The test machine HOUNSFIELD with capacity $20 \mathrm{kN}$ load was used.

The conditions of the tensile tests are: The initial length between the clamps of the test machine is $100 \mathrm{~mm}$ and the loading speed is $10 \mathrm{~mm} / \mathrm{min}$. The modulus of elasticity (Tab. 3) is obtained by two elongations by 4 and $8 \%$.

Table 3. Modulus of elasticity

\begin{tabular}{|c|c|c|}
\hline \multirow{2}{*}{$\begin{array}{c}\text { Modulus of elasticity for } \\
\text { elongations 4 / 8 \% [MPa] }\end{array}$} & \multicolumn{2}{|c|}{ Specimen width [mm] } \\
\cline { 2 - 3 } & 15 & 20 \\
\hline Longitudinal & $125 / 134$ & $155 / 183$ \\
\hline Transverse & $120 / 158$ & $125 / 173$ \\
\hline
\end{tabular}

The conditions of the tensile tests were: initial length between the clamps of test machine is $100 \mathrm{~mm}$, loading speed is $10 \mathrm{~mm} / \mathrm{min}$. The dependences from tensile tests for the specimens with different width from the tire casing 215/40 R17 are in Fig. 2. The moduli of elasticity were obtained by two elongations 4 and $8 \%$. The test data are used for verification analyses between calculated values and experimental data.

Next, the tests of low cyclic loading are realized for textile cap ply with PA66 on the test machine Autograph AG-X plus $5 \mathrm{kN}$ - Schimadzu with a video-extensometer. The specimens geometry is other than it was for tensile tests of structure parts of tire 215/40 R17. The geometric parameters of specimens are a length of $195 \mathrm{~mm}$, a width of $35 \mathrm{~mm}$, initial length between clamps of a test machine $100 \mathrm{~mm}$ and a thickness of the specimen of $1.05 \mathrm{~mm}$. The cord diameter is $0.5 \mathrm{~mm}$. The EPM is $870 \mathrm{~m}-1$. The initial length between the points for a video-extensometer is $50 \mathrm{~mm}$. The composite specimens with an angle of the textile reinforcement $0^{\circ}$ (textile reinforcement is perpendicular to the direction of loading) and $45^{\circ}$ are used for the cyclic tests. 


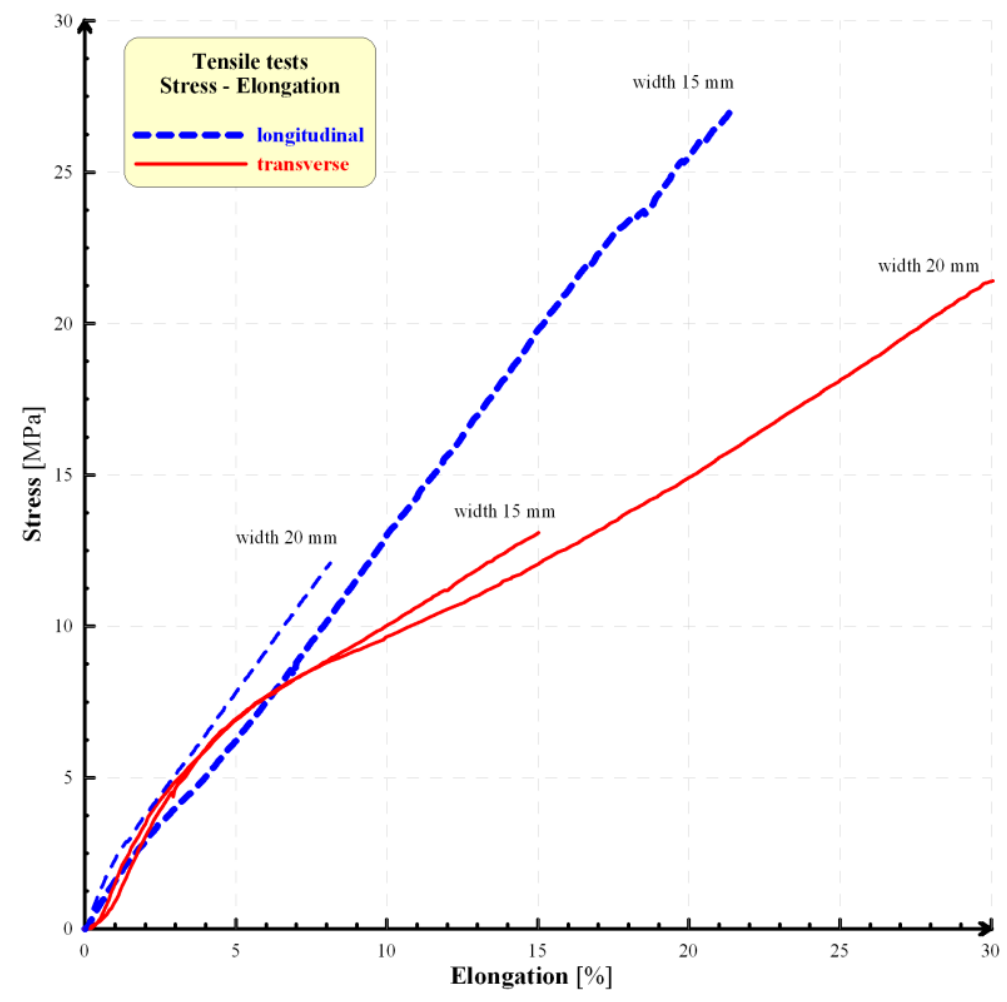

Fig. 2. Stress-strain dependencies of samples from tire casing 215/40 R17

The design of method for cycle loading tests of composites with a textile fiber and an elastomer matrix on a test machine with a video-extensometer has these conditions: the loading speed $250 \mathrm{~mm} / \mathrm{min}$ for cycles and $50 \mathrm{~mm} / \mathrm{min}$ for a pre-test by force value $2 \mathrm{~N}$ by standard [5]. Five cycle loops are applied. Every cycle loop consists of five cycles. Every cycle is defined as loading to a certain percentage of elongation between clamps of a test machine and unloading to a certain percentage of elongation between clamps of a test machine the first cycle loop consists of cycles with loading to $30 \%$ and unloading to $3 \%$ of elongation (not $0 \%$ because the negative force is not possible during tensile testing for certain composite specimens with the textile reinforcement). The second loop consists of cycles with elongation higher by $10 \%$ : loading to $40 \%$ and unloading to $10 \%$ of elongation. The third loop consists of five cycles that have loading to $50 \%$ and unloading to $20 \%$ of elongation, the fourth loop with cycles has loading to $60 \%$ and unloading to $30 \%$ of elongation. The fifth loop has cycles with different elongations, the loading to $60 \%$ is the same as fourth loop and unloading is $5 \%$ of elongation. The comparisons of the fifth cycles are given in Fig. 3 .

\section{Computational model}

The aim of this research work of authors is creation of computational models namely for stress-strain analyses of selected parts of radial tire casing [6]. The finite element method using the program system ANSYS is applied to the computational modeling.

For the description of the behavior of elastomers in a tire casing, there is the most commonly used the two-parameter Mooney-Rivlin material model. The Mooney-Rivlin model (M-R) is the most commonly used for computational modeling of tires. The M-R 
model can be well applied for the range of elongation up to $150 \%$. To determine the basic M-R parameters, it is necessary to carry out the tensile test for elastomer samples. These parameters describe the strain-stress behavior of elastomer parts of a tire casing. Next tests of elastomer parts of a tire casing are needed for the determination of parameters $\mathrm{C}_{10}$ and $\mathrm{C}_{01}$ of the Mooney-Rivlin model.

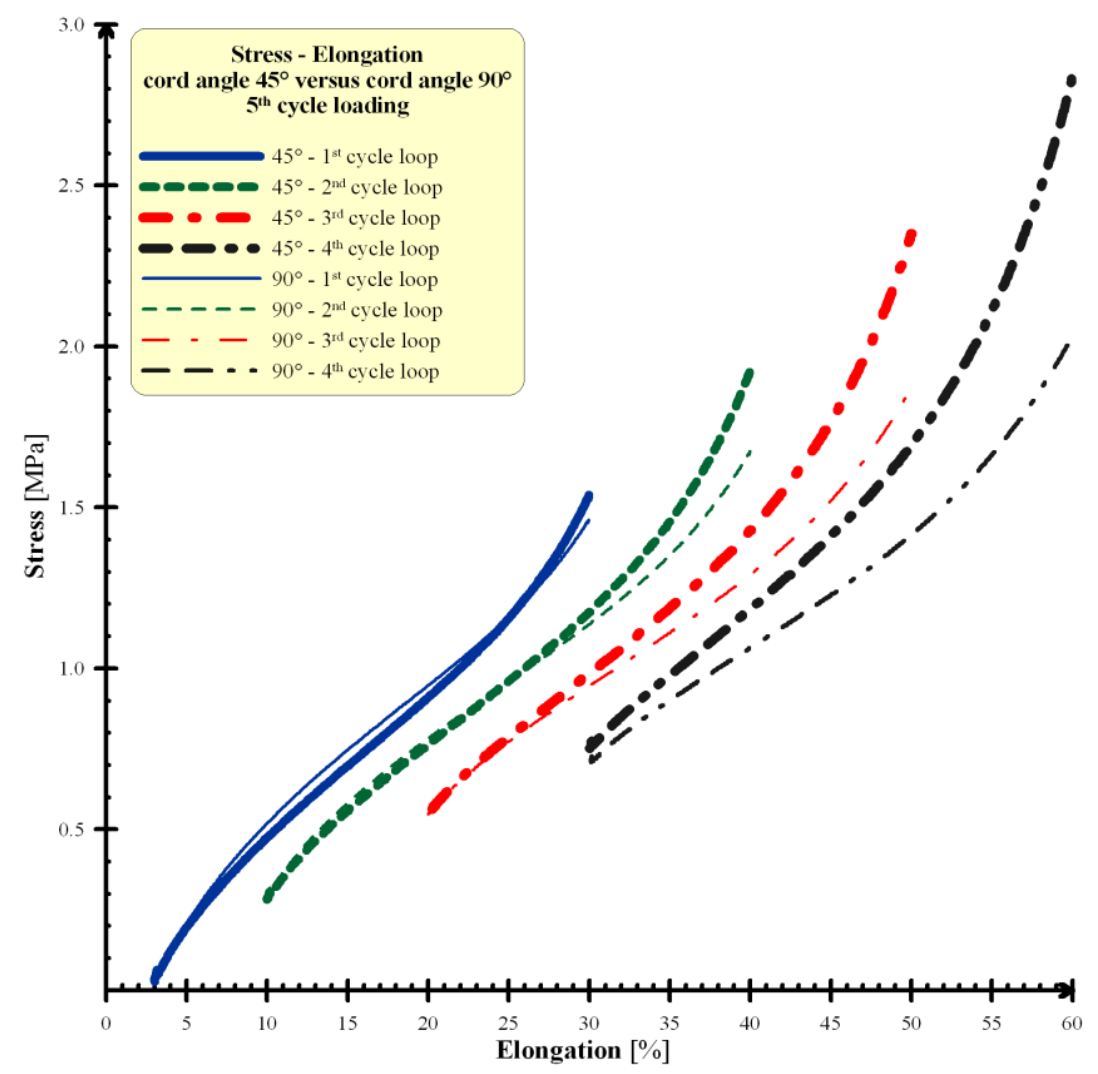

Fig. 3. Dependences of stress on elongation for fifth cycles

The M-R parameters are $0.638 \mathrm{MPa}$ (as $\mathrm{C}_{10}$ in ANSYS) and $0.284 \mathrm{MPa}$ (as $\mathrm{C}_{01}$ in ANSYS) and incompressibility parameter is $0.151 \mathrm{MPa}^{-1}$.

The computational model is presented in Fig. 4. The Solid 186 element type is used. The model has a length of $120 \mathrm{~mm}$ and the initial length between the clamps of the test machine $100 \mathrm{~mm}$ is defined by boundary conditions - by removing of degrees of freedom in two axes and applying displacements on the selected nodes in areas of clamps). The model is reverse loaded, the displacement in $z$-axis is defined and reaction force at the area of a sliding clamp of the test machine is searched. It is better for quick convergence and speed solution. The PCG solver is used. The increment of every substep is $0.2 \mathrm{~mm}$ in z-axis.

On the longitudinal edges of the model, there is characteristic "dentation" because the computational model is designed by APDL (ANSYS Graphical User Interface) procedures for the automatic creation of models from geometric parameters such as a cord diameter, cord distance and thickness of layer. 


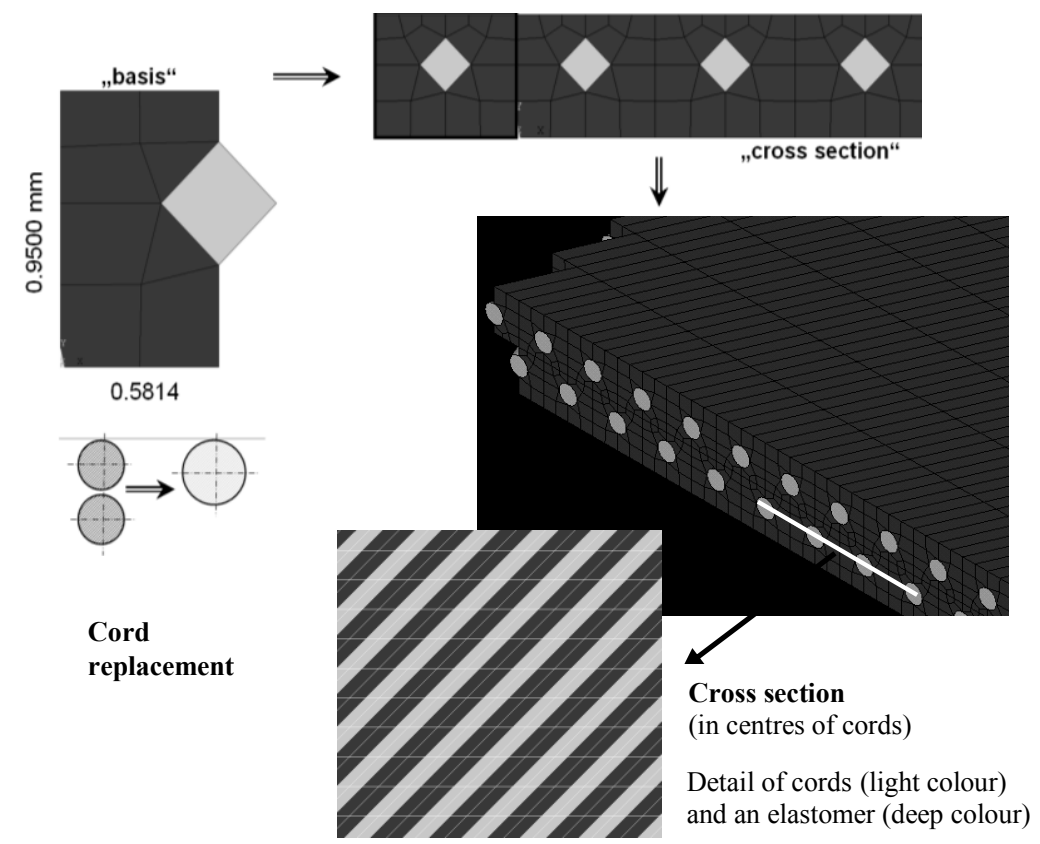

Fig. 4. Computational model of a specific layer of a steel-cord belt with the cross-sections of the model

\section{Discussion}

The approximate the dependences for a cord angle of $90^{\circ}$ (Fig. 3) can be used as input material parameters of an elastomer matrix. The fifth cycle in every cycle loop can be considered as a stable cycle. The values of true stress for a cord angle of $45^{\circ}$ are approximately $20-25 \%$ higher than values for a cord angle of $90^{\circ}$.

The results from computational modeling of one layer of specific composite parts of a tire casing as length displacement ( $z$-axis) and width displacement ( $x$-axis) for elongation of $5 \mathrm{~mm}$ are in Figs. 5 and 6 and for elongation $10 \mathrm{~mm}$ in Figs. 7 and 8 . The values of reaction forces are $14.8 \mathrm{~N}$ for elongation of $5 \mathrm{~mm}$ and $28.5 \mathrm{~N}$ for elongation of $10 \mathrm{~mm}$. From test data, the tensile force $16.3 \mathrm{~N}$ causes the deformation of $5 \mathrm{~mm}$ and force $27.4 \mathrm{~N}$ causes the deformation of $10 \mathrm{~mm}$. The computational model has tensile stiffness and the forces very similar. The force value differences between experiment and computation are $9.2 \%$.
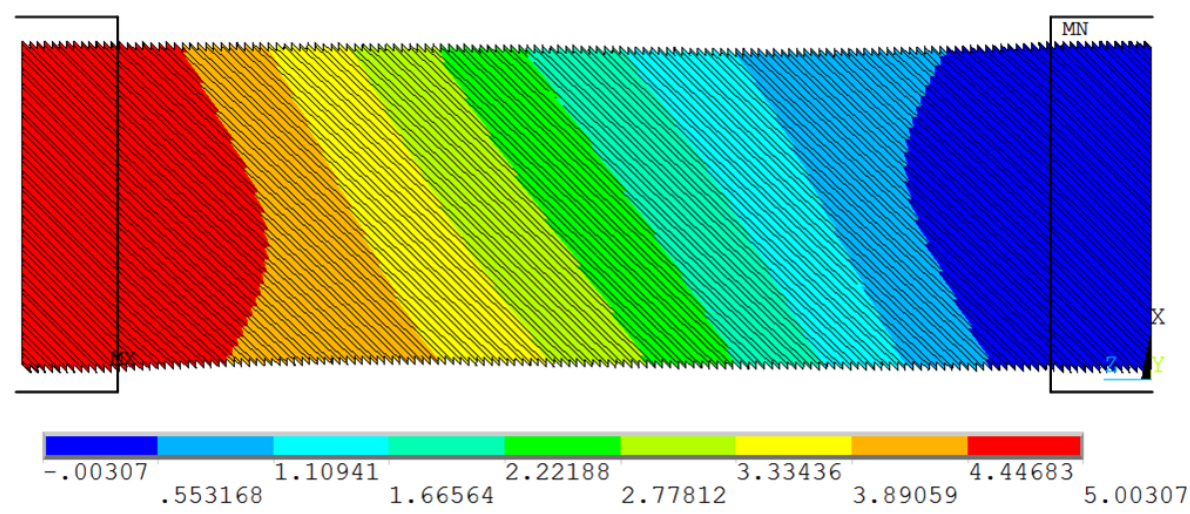

Fig. 5. Displacement in z-axis (length) for elongation $5 \mathrm{~mm}$ 

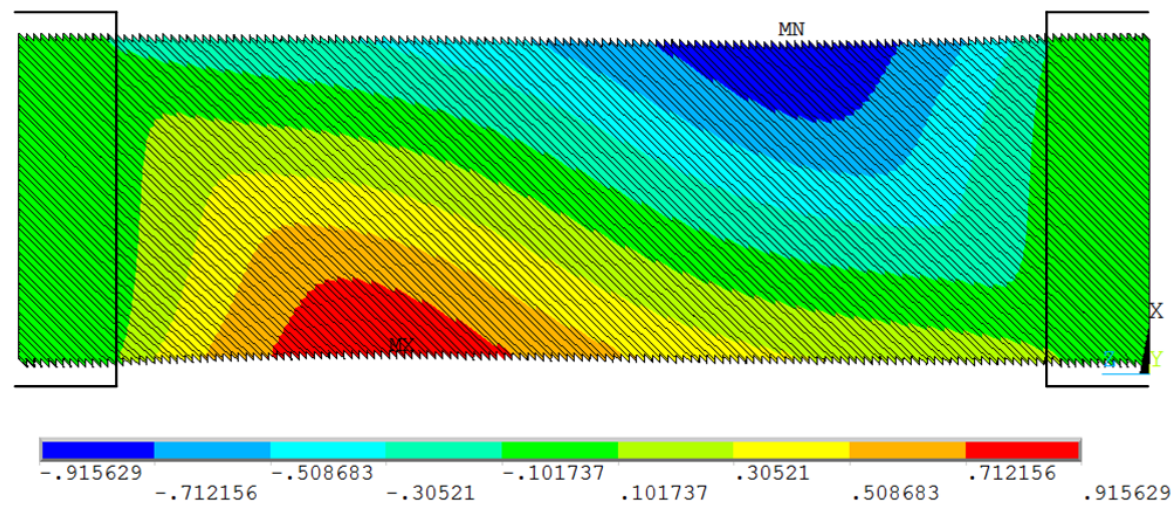

Fig. 6. Displacement in $x$-axis (width) for elongation $5 \mathrm{~mm}$

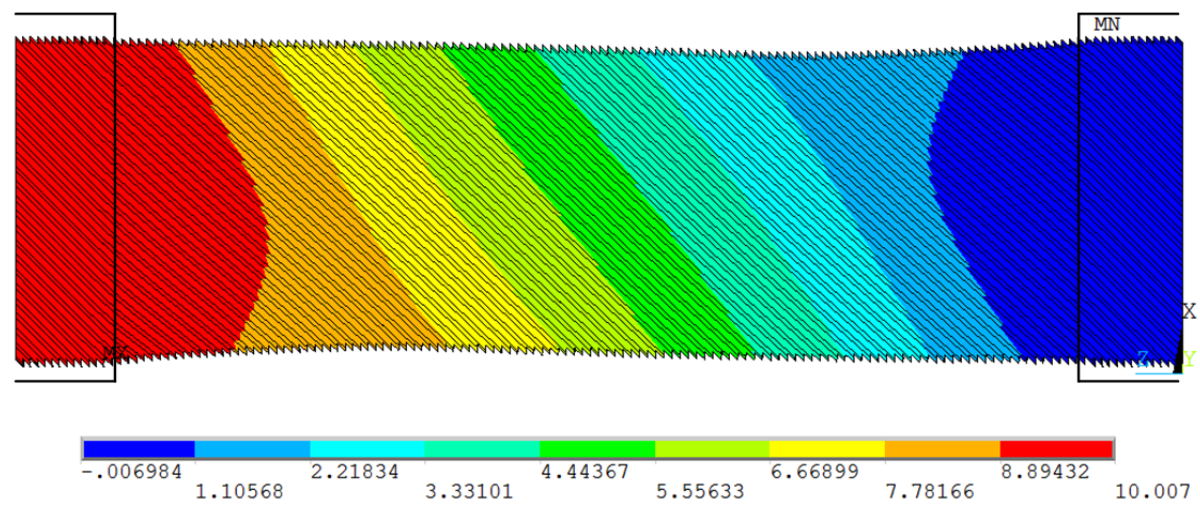

Fig. 7. Displacement in $z$-axis (length) for elongation $10 \mathrm{~mm}$
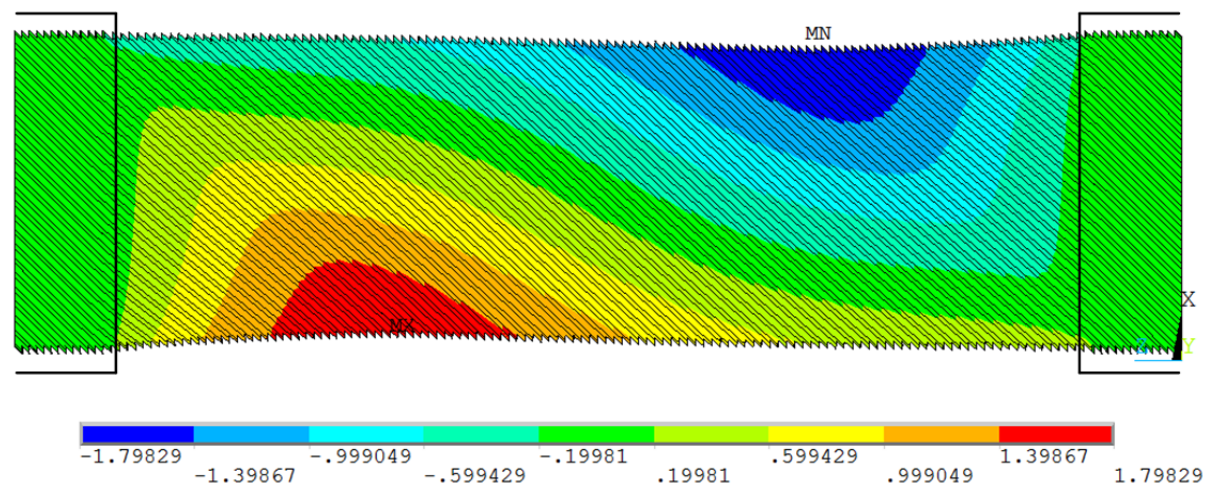

Fig. 8. Displacement in $x$-axis (width) for elongation $10 \mathrm{~mm}$ 


\section{Conclusions}

Methods for testing of textile composites with five cycle loops for different elongation with five cycles in every cycle loop have been designed. The fifth cycle in every cycle loop can be considered as a stable cycle because difference between fourth and fifth cycle is small (about to $5 \%$ ).

It is quite difficult to compare the results from the calculations with the data or outputs in literatures because each one author deals either with the different dimensions of specimens or applies any other material parameters and material models for the computational modeling of parts of tire casing.

The test machine has temperature chamber allowing the tests from -70 to $180{ }^{\circ} \mathrm{C}$ and from 20 to $80{ }^{\circ} \mathrm{C}$, it is possible to change the humidity from 30 to $95 \%$. Future research is needed for the tests of cyclic loading of composites, which will be realized at different temperatures. These results can be used in such conditions where the mentioned composites are exposed to the cyclic loading at an unsteady temperature: tire casing, conveyor belts, etc. The experiment results can be used for the optimization of the deposition angle of textile reinforcement in composites.

The contribution was supported by the Cultural and Educational Grant Agency of the Slovak Republic (KEGA), grant No. KEGA 005TnUAD-4/2016 and the project „Centrum pre testovanie kvality a diagnostiku materiálov“ ITMS code 26210120046 of the Operational Program Research and Development funded from European Fund of Regional Development.

\section{References}

1. P. Koštial, J. Krmela, K. Frydrýšek, I. Ružiak, The Chosen Aspects of Materials and Construction Influence on the Tire Safety. Composites and Their Properties, InTech, 265-298 (2012), DOI: 10.5772/48181

2. Composite authors, Rubber Technology. (GC Tech Peter Gerši, ISBN 80-969189-5-8, 2006)

3. The Pneumatic Tire. Eds.: A. N. Gent, J.D. Walter, (2006)

4. J. Krmela, V. Krmelová, Tire casing and their material characteristics for computational modeling of tires. $16^{\text {th }}$ International Scientific Conference Engineering for Rural Development, 206-211 (2011), DOI: 10.22616/ERDev2017.16.N043

5. DIN 53835-13: Testing of textiles; determination of the elastic behaviour of textile fabrics by a single application of tensile load between constant extension limits. (1993)

6. J. Krmela, V. Krmelová, Replacement of Belt Structure for FEA of Tire. Procedia Engineering 136, 132-136 (2016) 